\title{
DEVELOPMENT OF HRM FRAMEWORK FOR QUALITY MANAGEMENT: EMPIRICAL ANALYSIS OF HRM CHALLENGES
}

\author{
LEENA FRANCIS ${ }^{1} \&$ C. SENGOTTUVELU ${ }^{2}$ \\ ${ }^{1}$ Research Scholar, Bharathiar University, Coimbatore, Tamil Nadu, India \\ ${ }^{2}$ Professor \& Head-Consultancy, SCMS Cochin School of Business, \\ Prathap Nagar, Muttom, CochinKerala, India
}

\begin{abstract}
The paper attempted to make an empirical analysis of the HRM challenges to quality management and to develop a HRM framework that can support quality transformation. The three factors, namely, presence of HRM practices, HRM Administrative outcomes and HR deliverables for quality management was analyzed in detail bringing in their associations and mutual impacts. Hospitals with quality certification, hospitals that have initiated the quality certification process and hospitals, which had quality certification was selected for the research. The study used qualitative data collected from healthcare employees in Kerala collected through structured questionnaires, supplemented by secondary data and literature review. The collected data were analyzed and interpreted using frequency, percentage and Chi-Square. The paper concluded that the HRM challenges and issues of quality management and transformation is not the absence of HRM activities, but the negative outlook of top management towards investments in human resources. Though Human Resource Management practices are implemented as part of quality management, the administrative outcomes which are supposed to follow are missing in the majority of the cases. This adversely affects the expected HR deliverables and results in failure of quality management initiative.

KEYWORDS: Human Resource Management Framework, Quality Management, Quality Transformation, HRM Challenges \& Healthcare Sectors
\end{abstract}

Received: Aug 18, 2017; Accepted: Sep 04, 2017; Published: Sep 11, 2017; Paper Id.: IJHRMROCT20173

\section{INTRODUCTION}

The present era is the time of patient centered service and Kerala healthcare sector is currently at a stage of transformation in view of quality. In a way, this development can be viewed as a forced progression which is the result of increased patient expectation of service quality and cut-throat competition. However, the attempts to nurture quality improvements in the service sector faces failures on a large scale, mainly because the final products of health care services are difficult to measure (Piligrimien, \& Buiknien, (2008)., Feldman, 1994 and Rehin \& Raveendran, 2013).

The absence of an integrated system and the failure to see the organization as one single system (Reed, Lemak \& Mero 2000), the prescribed mode of quality transformation instead of participative mode, which does not take into consideration all the subsystems (Boyne \& Walker 2002) etc. are identified as some of the major whys and wherefores of quality transformation failures. Any organizational transformation must happen mainly in two perspectives. As seen by the seven ' $S$ ' model, change in the soft elements like skills, shared values, staff and style along with a change in the hard elements - strategy, structure and systems. While addressing the concept of 
quality transformation, the inclination of the top management usually is towards the hard ' $\mathrm{s}$ ' variables - making modifications in the strategy, structure and systems with the expectation that the rest of the variables will follow. But in most of the cases, the soft elements are difficult to label and are more concrete in its existence. Thus, the penetration of the quality concept gets limited and generally it does not reach the middle or the bottom level.

The paper focuses on the Human resource management initiatives taken by organizations for quality transformation, the outcome that should follow and the expected end results. All the quality gurus and scholars have highlighted human resource focus, in terms of effective training and employee involvement as one of the top driving forces of quality transformation (Walumbwa \& Lawler 2003, Reed, et al., 2002). Employee empowerment, improving employee morale and development and growth is the major facets of employee focus.

\section{BACKGROUND OF THE STUDY}

In the context of Kerala Healthcare sector, Quality management is in its middle conception stage. Hence, the researches done in this area are quite few. Articles published on why and how the HRM activities fails to support Quality Management initiatives are even more limited. The majority of the investigations done in this field were to focus mainly on the HRM initiatives that need to be implemented, ignoring the importance of administrative outcomes. Moreover, there are no well-established HRM frameworks or model that can be used by healthcare managements to enable the employees to support quality management initiatives.

\section{STATEMENT OF THE PROBLEM}

Quality transformation is an organizational change and any organizational change should have "change in process", "change in functions", "change in values" and "change in power within the organization". The organizations implementing quality initiatives tend to focus more on the first aspect, the change in the process (Cao, et al., 2000). Planning and introduction of a system directly comes from the top management but the middle and lower level employees perceive the change mainly through its tangible outcomes. The purpose of the study primarily is to understand whether the HRM initiatives are successful in communicating the advancements in system, structure and strategy as part of quality transformation to the middle level and bottom level employees in a hospital set up.

\section{OBJECTIVES OF THE STUDY}

- To study how the HR practices / interventions are followed by administrative outcomes in the Kerala healthcare sector.

- $\quad$ To evaluate the effectiveness of HR practices in generating the HR deliverables for quality management.

- $\quad$ To develop an HRM framework for quality management.

\section{RESEARCH METHODOLOGY}

The study is a combination of exploratory and descriptive research, using qualitative data collected through the interview method of adopting the questionnaire method.

\section{Sample Design}

The population of the research being the employees working in hospitals that falls into three main categories, 
quality certified hospitals (NABH or ISO or safe-I), hospitals in the process quality accreditation and hospitals which had quality certification earlier. From the hospitals under study one third of the population is selected as samples through convenience sampling method and the total sample size for the study is 1500 .

\section{Data Collection and Analysis}

The simple naming convention is used to denote the factors under study for convenience and easy understanding. The first factor considers the regular HRM activities like HRP, Job analysis, Recruitment based on HRP and Job analysis, Performance Appraisal, documented disciplinary procedure, Employee satisfaction surveys, Grievance handling procedures, Training and is denoted by the term "HRM practices". The second factor analyzed is the employee benefits and job-related sustenance like financial benefits, nonfinancial benefits and rewards, Feedback and development initiatives, Job enrichment, Optimum resources and role clarity. These are expected to happen following the HRM practices and are denoted as "Administrative outcomes". The third factor under study is termed as "HR indicators / enablers for quality management", such as better discipline and systematic work pattern, employee commitment and retention, employee empowerment and development, organizational citizenship\& flexibility and employee involvement. A set of structured questionnaires using five-point scale were used to collect data. The secondary data has been collected from journals, websites, magazines and publications. The collected data had been analyzed and interpreted with the help of Chi- square, frequency analysis and percentage using SPSS - 17.0 versions.

\section{Formulation of Hypotheses}

For the study three research hypotheses are formulated. The details are as follows:

Hypothesis 1: There is a significant relation between HRM interventions / practices and the expected administrative outcomes (to the employees).

Hypothesis 2: There is a significant relation between HRM interventions / practices and the HR enablers / indicators for quality management.

Hypothesis 3: There is a significant relation between expected administrative outcomes of HR practices and the HR enablers / indicators for quality management.

\section{ANALYSIS AND INTERPRETATION OF RESULTS}

\section{HR Practices Compliance at the hospitals}

Based on the data collected, the implementation of HRM practices was analyzed. The below table describes the hospital's compliance with the different HRM practices considered.

Table 1: HR Practices Compliance at the Hospitals

\begin{tabular}{|l|c|}
\hline \multicolumn{1}{|c|}{ HR Practices } & Percentage \\
\hline Human Resource Planning & 73.0 \\
\hline Foreword integrated Recruitment & 69.2 \\
\hline Documented disciplinary procedure & 55.0 \\
\hline Performance Appraisal & 100.0 \\
\hline Employee satisfaction survey & 53.8 \\
\hline Employee suggestion schemes & 99.0 \\
\hline Training program & 76.9 \\
\hline Job specification and Job description & 95.0 \\
\hline
\end{tabular}




\begin{tabular}{|l|c|}
\hline Documented Grievance handling procedure & 70.0 \\
\hline Job Evaluation and Compensation Management & 78 \\
\hline
\end{tabular}

Source: Primary data collected by the Author

From the above table, it can be inferred that the majority of the hospitals under study has implemented HR interventions. Based on theoretical assumption, the HR practices should support the quality transformation process and the HR deliverables. As the hospitals considered for study are either quality certified or in the process of quality certification, it is mandatory to have these HR practices. The human resource focus is one of the important attributes of quality accreditation (R.K. Madhu, 2005) and the questions regarding the HRM practices forms one major part of the assessment tool kit. So, the institutions irrespective of their functional domain, tries to implement HR related activities at least as the last step of quality transformation. Even as part of the study it was observed that some of the hospitals established the HR department quite recently.

\section{HRM Practices Expected Administrative Outcomes to the Employees}

The administrative outcomes of HRM practices are the benefits and opportunities given to the employees based on the analysis and procedures done as part of HRM activities. It comprises the financial benefits, non-financial rewards and recognition, feedback and developmental initiatives, job enrichment and optimum resources and role clarity. The study analyzed whether the HRM initiatives were followed by the expected administrative outcomes.

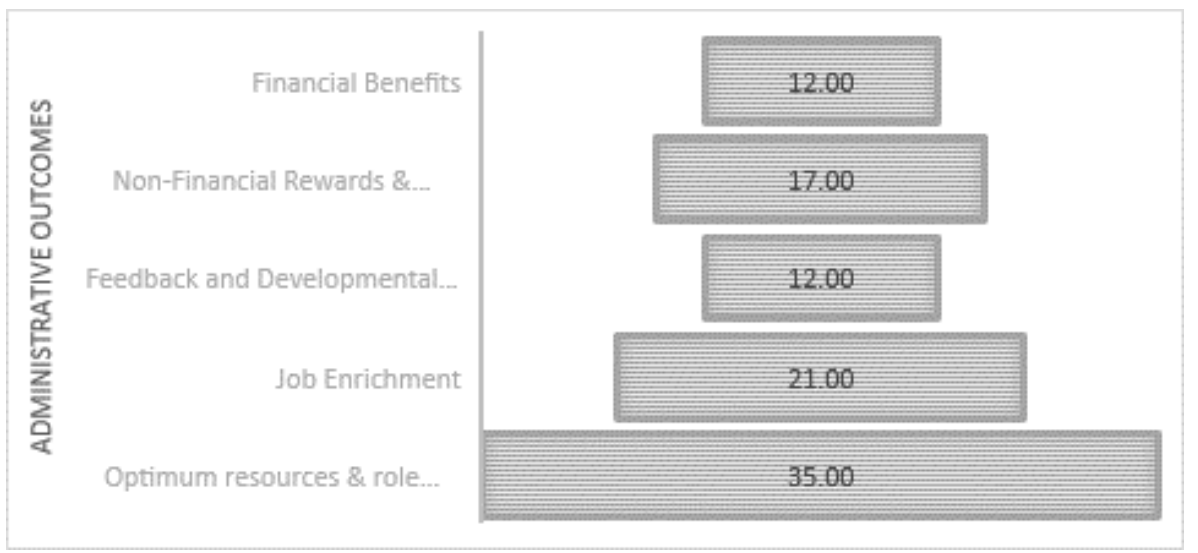

Figure 1: Presence of HRM Practices Administrative Outcomes at the Hospitals

Every HR activity is done with a specific purpose. HRM activities are expected to produce certain administrative outcomes, which show the performance reward relationship. From the above diagram, it can be inferred that the HRM practices were not followed by administrative outcomes though it is expected. The major areas of deviations are with respect to financial and non-financial rewards. The healthcare sector of Kerala is always subject to criticism in terms of providing monetary and non-monetary benefits to the employees. The performance appraisal process is the first step in reward management. All the hospitals under study has performance appraisal, but its purpose as a method of employee feedback, performance counseling, performance coaching and to become the basis of promotion, salary increase and counseling are virtually absent. From the data, it can also be observed that the employees feel positive about the availability of resources and role clarity. The feedback and developmental strategies are on a negative note. Therefore, it can be inferred that the HR practices are successful in implementing systems and procedures, but fails in uplifting the employee morale through rewards, recognition and developmental initiatives. The hospitals have suggestion schemes and 
satisfaction surveys, but the management commitment in the process is peripheral. The suggestion schemes are not progressive and the managements fail to remove fear of being penalized for being the whistle blowers.

\section{HR Enablers / Indicators for Quality Management}

The below graph plots the type of impression the HR practices creates in the mindset, attitude and involvement of employees. The result of the HRM practices in bringing out the best contribution from the employees is analyzed below. The main positive impact created by HRM interventions is the imparting of better discipline and systematic work pattern in the organization. The HR initiatives support employee discipline as it brings out a process and system.

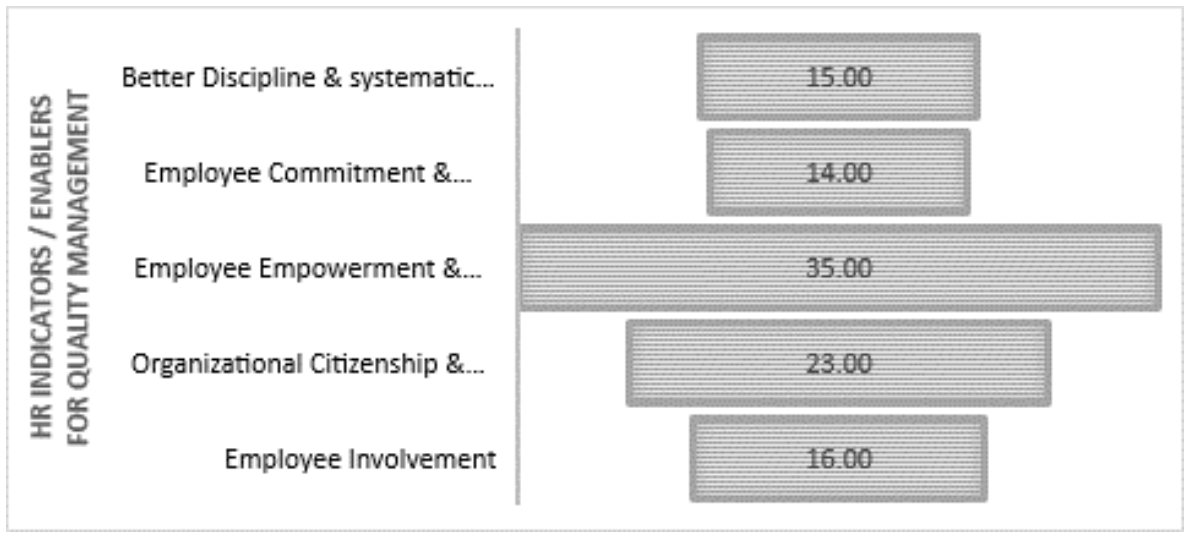

Figure 2: Level of HR Indicators / Enablers for Quality Management at the Hospitals

Since performance appraisal is not followed by the expected administrative outcomes of the management, it does not significantly support in increasing employee motivation, morale and commitment. Many of the employees feel that the quality documentation activities affect the regular work schedules and quality documentation as an additional burden especially for nurses. The major reason for this crisis is, though hospitals have made changes in their pattern of work and recording, significant changes in resources and infrastructure is not made. Speaking about the training programs, the hospitals have a training budget, training modules, set training man-hours and regular training programs it is a positive step toward employee empowerment and development, but the negative side is that the training modules are not developed in consultation with the employees or it is not based on performance appraisal. The employees tend to view the training program as an initiative forced upon them rather than as a support activity.

\section{Statistical Analysis of Significance of Relationship}

Hypothesis 1: There is a significant relation between HRM practices and the expected administrative outcomes (to the employees).

Table 2: Chi-Square test of Independence Indicating the Statistical Significance Relationship Between the HRM Activities and the Administrative Outcomes that Should Follow

\begin{tabular}{|l|c|c|c|}
\hline & Value & Df & Asymp. Sig. (2-Sided) \\
\hline Pearson Chi-Square & 0.47 & 2 & .828 \\
\hline Likelihood Ratio & 0.47 & 2 & .828 \\
\hline Linear-by-Linear Association & 0.47 & 2 & .829 \\
\hline N of Valid Cases & 2509 & & \\
\hline
\end{tabular}

Note: 0 cells $(.0 \%)$ has expected count less than 5 . The minimum expected count is 12.56

The above analysis shows that the relationship between the HRM practices and the administrative outcomes is not 
significant as the calculated value is less than chi-square critical value. Hence, the null hypothesis is accepted and the alternative hypothesis is rejected.

Hypothesis 2: There is a significant relation between HR practices and the HR enablers / indicators for quality management.

Table 3: Chi-Square Indicating the Statistical Significance Relationship between the HRM Activities and the HR Deliverables for Quality Management

\begin{tabular}{|l|c|c|c|}
\hline & Value & Df & Asymp. Sig. (2-Sided) \\
\hline Pearson Chi-Square & .156 & 1 & .693 \\
\hline Likelihood Ratio & .156 & 1 & .693 \\
\hline Linear-by-Linear Association & .156 & 1 & .693 \\
\hline N of Valid Cases & 2509 & & \\
\hline
\end{tabular}

Note: 0 cells $(.0 \%)$ has expected count less than 5 . The minimum expected count is 14.56

From the above analysis, it can be inferred that the relationship between the HRM practices and the expected employee attitude for quality management is not significant as the calculated value is less than chi-square critical value. Hence, the null hypothesis is accepted and the alternative hypothesis is rejected.

Hypothesis 3: There is a significant relation between expected administrative outcomes of HRM practices and the HR enablers / indicators for quality management.

Table 4: Chi-Square Indicating the Statistical Significance Relationship between the Administrative Outcomes of HR Practices and the HR Enablers / Indicators for Quality Management

\begin{tabular}{|l|c|c|c|}
\hline & Value & Df & Asymp Sig. (2-Sided) \\
\hline Pearson Chi-Square & 35.930 & 1 & .000 \\
\hline Likelihood Ratio & 37.831 & 1 & .000 \\
\hline Linear-by-Linear Association & 35.830 & 1 & .000 \\
\hline N of Valid Cases & 2509 & & \\
\hline
\end{tabular}

Note: 0 cells $(.0 \%)$ has expected count less than 5 . The minimum expected count is 49.44 .

From the above analysis, it can be seen that the relationship between the Administrative outcomes of HR activities and the HR deliverables for Quality Management is significant as the calculated value is higher than chi-square critical value. Hence, the alternative hypothesis is accepted and the null hypothesis is rejected.

Based on the above three analyses, it can be inferred that there is no significant association between the presence HRM practices and the expected administrative outcomes in the hospitals under study Though HRM practices are expected to be followed by administrative outcomes that can improve the employee experience with the organization, the top management may have failed in transferring the benefits to the employees or in recognizing the importance of employee benefits and employee support activities. The second analysis clearly shows that in the hospitals understudy, the relation between HRM practices and employee attitude towards quality management is insignificant. Accordingly, it shows an unconventional result that HRM practices did not support in generating the expected positive attitude among the employees. Further, there is significant statistical relation between the administrative outcomes and the expected employee attitude for quality management. Based on the three relationships identified, it can be generalized that the HRM practices becomes an employee engagement activity only when sufficient administrative outcomes are followed, otherwise it will be observed and understood as a mere paper work. 


\section{DISCUSSIONS \&CONCLUSIONS}

\section{Discussions \& Recommendations}

The outcomes of HR practices were limited as the HR practices were not followed by administrative outcomes. The HRM practices should be directed towards improving employee commitment and employee involvement in Quality management.

- The performance appraisal needs to be treated as a serious activity with performance counseling and feedback, employee improvement program and corrective actions to support role clarification, rewards and progression based on performance.

- Improve employee awareness about the importance of the quality support activities through proper rewards and recognition programs, team activities like quality circles, QWL groups, quality functional deployment etc.

- The HR practices should be done with proper consultation and understanding with the employees. Some of them observed are training, suggestion schemes, performance appraisal, reward management, etc. The training programs need to be initiated based on employee requirements through proper Performance appraisal and training need evaluation or similar processes.

- Increasing employee involvement and participation through the initiation of a progressive and simplified suggestion program is important in encouraging employee citizenship with the organization.

\section{HRM Framework for Quality Management}

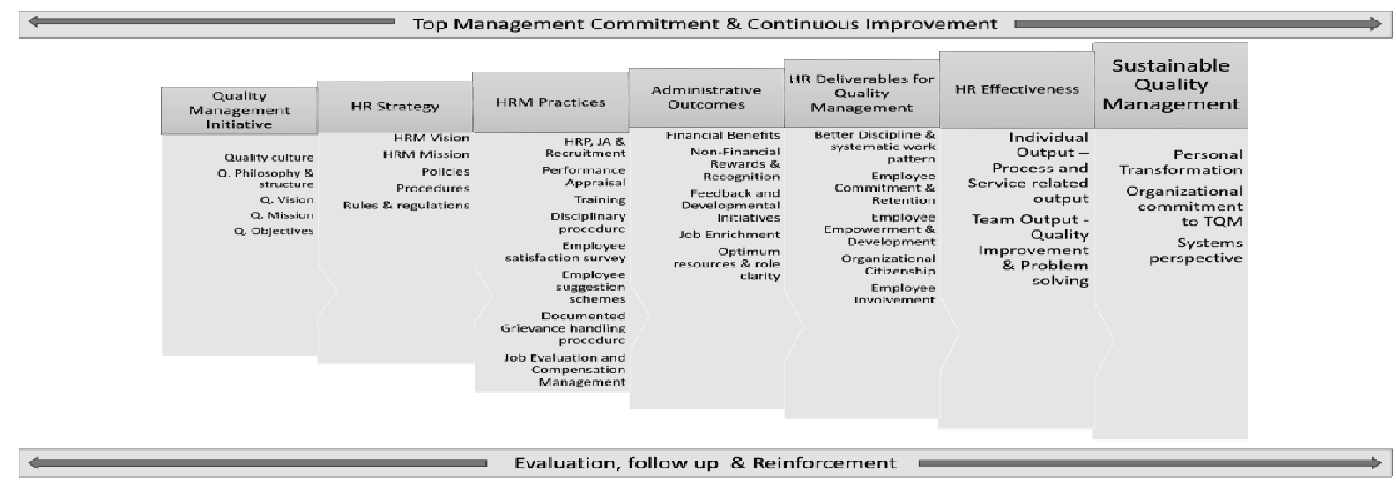

Figure 3: HRM Framework for Quality Management

Source: This framework is created by the Author

The above given is the HRM framework for quality management. The process of human resource management should commence with the development of a quality vision, mission, philosophy, structure and objectives. All these factors will together support the development and growth of quality culture. The second step is the development of HR strategy based on the quality management initiative. It comprises of the HR vision, mission, policies, procedure and rules and regulations.

The HR practices should be implemented in line with the HR strategy and it must be followed by administrative outcomes which can support the HR enablers. The HR enablers will support the individual as well as team output in terms of process improvement, quality improvement and problem solving. The outputs will take care of the sustainable quality 
initiative and management. All the activities and all the stages of development is possible only with top management commitment, continuous improvement, evaluation, feedback and reinforcement.

\section{CONCLUSIONS}

Quality management in the healthcare sector is assumed to be a complicated process, as the outcomes of the efforts are neither comparable nor directly measurable (Piligrimien \& Buiknien, 2008). This shows the significance of a highly planned and well executed quality system, for the health care sector. The study offers empirical evidence, to prove the relation between HRM activities, administrative outcomes and HR enablers for quality. Hence, the HRM obstacle to quality management is not the absence of HRM activities, but the absence of outcomes to the employees. The present research supports the other researchers' findings, that the failure of quality initiatives can be attributed to the factors like lack of human resources development and management, lack of planning for quality; lack of leadership for quality; inadequate resources and lack of top management commitment (Sebastianelli, R., \& Tamimi, N., 2003 \& Bhat, K. S., \& Rajashekhar, J., 2009). The tendency to skip the output levels may create negative results instead of positive support. The management must update themselves on the quality management practices, and the ways to increase HR participation, other than just implementing HR practices. (Oke, M. A., \& Oke, O. D. 2014)

\section{REFERENCES}

1. Bhat, K. S., \& Rajashekhar, J. (2009). An empirical study of barriers to TQM implementation in Indian industries. The TQM Journal, 21 (3), 261-272.

2. Boyne, GA \& Walker, RM 2002, 'Total Quality Management And Performance An Evaluation of Evidence and Lessons for Research on Public Organizations', Public Performance \& Management Review, vol. 26, no. 2, pp. 111-131.

3. Cao, G., Clarke, S., and Lehaney, B. (2000). A systemic view of organizational change and TQM. The TQM Mag. 12, 186193.

4. Feldman, M. P. (1994). “Knowledge Complementarity and Innovation.” Small Business Economics, 6 (5): 363-372.

5. Oke, M. A., \& Oke, O. D. (2014). Exploring the Link between Total Quality Management and Business Performance. European Journal of Business and Management, 6 (9), 75-86.

6. Piligrimien, \& Buiknien, (2008). Different Perspectives on Health Care Quality: Is the Consensus Possible? Engineering Economics, (1 (56), 104-110.

7. Reed, R, Lemak, DJ \& Mero, NL 2000, 'Total Quality Management and sustainable competitive advantage', Journal of Quality Management, vol. 5, pp. 5-26.

8. Lemak, David J., Neal P. Mero, and Richard Reed. "When quality works: A premature post-mortem on TQM." Journal of Business and Management 8.4 (2002): 391.

9. Rehin, K. R., \& Raveendran, P. T., 2013, Antecedents of Patients' Satisfaction at Government Hospitals in Kerala: An Exploration. Commerce Spectrum, 73.

10. Sebastianelli, R., \& Tamimi, N. (2003). Understanding the obstacles to TQM success. Quality Management Journal, 10 (3).

11. Walumbwa, FO \& Lawler JJ 2003, 'Building effective organizations: transformational leadership, collectivist orientation, work related attitudes and withdrawal behaviors in three emerging economies', Human Resource Management, vol. 14, no. 7, pp. 1083-1101. 